\title{
Red disperse dyes (DR 60, DR 73 and DR 78) at environmentally realistic concentrations impact biochemical profile of early life stages of zebrafish (Danio rerio)
}

\author{
Gabriela Meireles $^{\mathrm{a}, \mathrm{b}, *}$, Michiel A. Daam ${ }^{\mathrm{c}}$, Ana Letícia Madeira Sanches ${ }^{\mathrm{b}, \mathrm{d}}$, Maria V.B. Zanoni ${ }^{\mathrm{e}, \mathrm{g}}$, \\ Amadeu M.V.M. Soares ${ }^{\mathrm{b}}$, Carlos Gravato ${ }^{\mathrm{f}}$, Danielle P. de Oliveira ${ }^{\mathrm{a}, \mathrm{g}}$ \\ a School of Pharmaceutical Sciences of Ribeirão Preto, University of São Paulo, 14040-903, Ribeirão Preto, São Paulo, Brazil \\ b Department of Biology and CESAM, University of Aveiro, 3810-193, Aveiro, Portugal \\ ${ }^{\mathrm{c}}$ CENSE, Department of Environmental Sciences and Engineering, Faculty of Sciences and Technology, New University of Lisbon, Quinta da Torre, 2829-516, Caparica, \\ Portugal \\ ${ }^{\mathrm{d}}$ NEEA/CRHEA/SHS, São Carlos Engineering School, University of São Paulo, 13560-970, São Carlos, São Paulo, Brazil \\ e Institute of Chemistry-State University "Julio de Mesquita Filho"-UNESP, 14800-900, Araraquara, São Paulo, Brazil \\ ${ }^{\mathrm{f}}$ Faculty of Sciences and CESAM, University of Lisboa, 1749-016, Campo Alegre, Lisboa, Portugal \\ ${ }^{g}$ National Institute of Science and Technology for Detection, Toxicological Evaluation and Removal of Emerging and Radioactive Contaminants (INCT-DATREM), \\ Conselho Nacional de Desenvolvimento Cientifico e Tecnologico (CNPq), Brasília, Brazil
}

\section{A R T I C L E I N F O}

\section{Keywords:}

Textile dyes

Oxidative stress

Neurotoxicity

Cellular energy allocation

\begin{abstract}
A B S T R A C T
Dyes have been used for more than twenty thousand years in textile, pharmaceutical, food, cosmetic, and photographic industries, among others. Despite their importance in these applications, dyes can be toxic and resistant to many degradation processes used in wastewater treatment plants. Although a large number of dyes have been released in the environments in high amounts, studies into the environmental toxicity of these substances are still scarce. The aim of this study was to evaluate the potential toxic effects of textile dyes Disperse Red 60, Disperse Red 73 and Disperse Red 78 in zebrafish early life stages. To this end, biochemical biomarkers were selected to evaluate non-enzimatic antioxidant (Total Glutathione), antioxidant enzymes (Glutathione Stransferase and Catalase), oxidative stress (lipid peroxidation), neurotransmission (acetylcholinesterase) and energetic metabolism parameters (energy available and energy consumed) after $96 \mathrm{~h}$ exposure to these dyes. Our results demonstrated that these disperse dyes induce biochemical alterations in zebrafish embryos at environmental realistic concentrations and that the discharge of these disperse dyes into water bodies should be carefully evaluated. The selected biomarkers were sensitive as early-warning endpoints of disperse dyes toxicity on zebrafish embryos. Implications for risk assessment and indications for future research are discussed.
\end{abstract}

\section{Introduction}

The aquatic environment is the major target of contaminants from industrial effluents [1-3]. The textile industry, for example, releases approximately $15-50 \%$ of the total amount of dyes used during manufacturing into the aquatic environment [3]. Due to their high persistence and general poor removal by conventional industrial wastewater treatments, dyes have been considered one of the most problematic water pollutants worldwide [4]. It has been estimated that approximately 10,000 different dyes and pigments are currently in industrial use, totalling an annual consumption of around 700 thousand tonnes worldwide $[5,6]$. In textile industry, up to 200 thousand tonnes of these dyes are lost to effluents every year during dyeing and finishing due to the inefficiency on the process [6]. To date, few studies have measured dye concentrations in water bodies [7]. In a study conducted on the Yamaska River (Quebec, Canada), Maguire and Tkacz [8] detected 15 dyes in water, sediment and suspended solids samples, and reported Disperse Blue 26, Disperse Blue 79 and Disperse Red 60 concentrations ranging from 3 to $17 \mu \mathrm{g} / \mathrm{L}$. In Brazil, dispersed dyes have also been detected, such as Disperse Red 1, Disperse Blue 373 and Disperse Violet 93, in samples from the Ribeirão dos Cristais and Piracicaba rivers, with dye concentration ranging from 0.002 to $3.5 \mu \mathrm{g} / \mathrm{L}[9,10]$.

Relatively few studies have been conducted so far on biochemical damages of dyes to aquatic organisms [11-14]. In addition, since

\footnotetext{
* Corresponding author. School of Pharmaceutical Sciences of Ribeirão Preto, University of São Paulo, 14040-903, Ribeirão Preto, São Paulo, Brazil.

E-mail address: gabi_meireles@yahoo.com.br (G. Meireles).
} 
environmental dye concentrations are often found at sublethal levels, sensitive methods are required to determine early-warning signs of adverse effects such as molecular, biochemical, or physiological responses rather than traditional acute $\mathrm{LC}_{50}$ (lethal concentration affecting $50 \%$ of the test population) bioassays $[13,15]$. Conjugation and antioxidant enzymes, such as, glutathione S-transferase and catalase have been considered effective indicators for the response of organisms to pollutant-induced oxidative stress $[11,16]$. Inhibition of acetylcholinesterase activity enzyme, involved in the breakdown of the neurotransmitter acetylcholine, has been proven to be a good indicator of chemical-induces neurotoxicity [17,18]. Energy budget-related parameters are also of great biological and ecotoxicological importance since they provide information about the available and consumed energy, as well as energy sources (proteins, lipids, carbohydrates) being used $[14,19,20]$. Detoxification responses induced by chemical stress in exposed organisms are energetically costly and may change the energy distribution between the physiological processes, which may alter their functioning [21].

Zebrafish (Danio rerio) early life stages have been commonly used as an alternative test method for conventional acute fish toxicity assays $[22,23]$. Several studies have used zebrafish early life stages to evaluate the toxicity of pollutants and emergent contaminants [24,25]. Few studies, however, have so far been conducted evaluating the effects of dyes on biochemical biomarkers in early life stages of zebrafish [13,14].

The assumption that substances with high molecular weight do not have access to the embryo due to the protective role of the chorion is one of the objections that have been made to the use of the fish embryo test (FET) [26]. However, disperse dyes are widely used in several industrial applications and have a low molecular weight, making them the smallest dye molecules among the dyes [27,28]. The aim of the present study was therefore to evaluate the toxicity of DR60, DR73 and DR78 on biochemical processes of early-life stages of zebrafish. To this end, a zebrafish early life stage test was conducted to evaluate the effects of these dyes on detoxification and antioxidant processes, oxidative damage, acetylcholinesterase activity and cellular energy allocation.

\section{Materials and methods}

\subsection{Test chemicals}

DR 60 was purchased from Huntsman Textile Effects (USA), whereas DR 73 and DR 78 were obtained from Classic Dyestuff INC (USA). Their main characteristics are provided in Fig. 1. Considering that these dyes are insoluble in pure water $[27,28]$, stock solutions of the test concentrations were prepared in culture medium containing $0.01 \%$ dimethyl sulfoxide (DMSO).

\subsection{Test organisms}

All embryos used in the present study were provided by the zebrafish facility established at the Department of Biology of the University of Aveiro (Portugal). In this facility, adult organisms are kept under controlled conditions in a ZebTEC (Tecniplast) recirculating system. Culture water in this test system is purified by reverse osmosis and activated carbon filtered tap water, complemented with salt "Instant Ocean Synthetic Sea Salt" (Spectrum Brands, USA) and automatically adjusted for $\mathrm{pH}$ and conductivity. Culture conditions are: temperature $=26.0 \pm 1{ }^{\circ} \mathrm{C}$; conductivity $=750 \pm 50 \mu \mathrm{S} ; \mathrm{pH}=7.5 \pm 0.5$; salinity $=0.35 \mathrm{ppt}$ and dissolved oxygen = equal or above $95 \%$ saturation, with a photoperiod of $14 \mathrm{~h}$ light $-10 \mathrm{~h}$ dark. Nitrogen compounds are regularly monitored to keep concentrations always below $0.1 \mathrm{mg} / \mathrm{L}$ (nitrate) and $0.01 \mathrm{mg} / \mathrm{L}$ (nitrite and ammonia). Adult fish are fed twice a day with commercially available artificial diet (ZM-400 fish food; Zebrafish Management Ltd).

Zebrafish eggs were obtained by breeding of fish in aquaria with marbles on the bottom to protect eggs from predation by adult fish. The eggs were collected, rinsed in water, and checked under a stereomicroscope (Stereoscopic Zoom Microscope-SMZ 1500, Nikon). Eggs with cleavage irregularities, injuries, or other kind of malformations were discarded.

\subsection{Experimental design}

The eggs obtained as described in section 2.2 were transferred to petri dishes containing $15 \mathrm{~mL}$ test solution each $(0.001 ; 0.01 ; 0.1$ and $1 \mathrm{mg} / \mathrm{L}$ to DR 60 and DR73 and $0.001 ; 0.01 ; 0.1 ; 1$; and $10 \mathrm{mg} / \mathrm{L}$ to DR 78) using twenty embryos per dish. Negative control (reverse osmosis water and $0.01 \%$ DMSO in reverse osmosis water v/v) were also analysed. The test was conducted under the same temperature $\left(26.0 \pm 1{ }^{\circ} \mathrm{C}\right)$ and light (14h light: $10 \mathrm{~h}$ dark) conditions as those in the adult fish culture. After $96 \mathrm{~h}$ post-fertilization (hpf) 8 clusters of 20 embryos each were collected per concentration and transferred to 2-mL microtubes after $96 \mathrm{~h}$ of exposure to dyes and submersed in liquid nitrogen and subsequently kept in a freezer at $-80^{\circ} \mathrm{C}$ until further analysis.

\author{
Disperse Red 60 \\ Molecular formula: $\mathrm{C}_{20} \mathrm{H}_{13} \mathrm{NO}_{4}$ \\ Molecular weigth: $331.32 \mathrm{~g} / \mathrm{mol}$ \\ Purity: $60-80 \%$
}<smiles>Nc1c(Oc2ccccc2)cc(O)c2c1C(=O)c1ccccc1C2=O</smiles><smiles>CCN(CCC#N)c1ccc(/N=N/c2ccc([N+](=O)[O-])cc2C#N)cc1</smiles>

\author{
Disperse Red 78 \\ Molecular formula: $\mathrm{C}_{17} \mathrm{H}_{16} \mathrm{CIN}_{5} \mathrm{O}_{2}$ \\ Molecular weigth: $357.71 \mathrm{~g} / \mathrm{mol}$ \\ Purity: $60-80 \%$ \\ Disperse Red 73 \\ Molecular weigth: $348.46 \mathrm{~g} / \mathrm{mol}$ \\ Purity: $60-80 \%$
}

Fig. 1. Selected chemical characteristic and molecular structures of the three dyes tested.

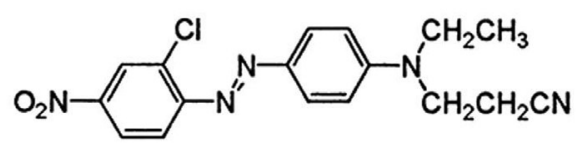




\subsection{Biochemical analysis}

On the day of biochemical analysis, $1.6 \mathrm{~mL}$ ultrapure water was added to the content of each microtube on ice, and subsequently homogenized using a sonicator (Ystral GmbH D-7801 Dottingen). Subsequently, the sample volume was subdivided as follows to analyse the different biochemical parameters:

- $300 \mu \mathrm{L}$ for lipid content;

- $300 \mu \mathrm{L}$ for protein reserves and carbohydrates content;

- $300 \mu \mathrm{L}$ electron transport system (ETS), which was mixed with $150 \mu \mathrm{L}$ ETS standard solution and centrifuged (1000 g; $4{ }^{\circ} \mathrm{C} ; 10 \mathrm{~min}$ ) for further ETS determination in the supernatant fraction;

- $200 \mu \mathrm{L}$ for lipid peroxidation to which $4 \mu \mathrm{L}$ 2,6-di-tert-butyl-4-methylphenol solution ( $4 \% \mathrm{v} / \mathrm{v}$ in methanol) was added;

- $500 \mu \mathrm{L}$ for total glutathione (TG), glutathione-S-transferase (GST), catalase (CAT), acetylcholinesterase (AChE) and the protein content determination, which was mixed with $500 \mu \mathrm{L}$ phosphate standard solution ( $0.2 \mathrm{M} ; \mathrm{pH}=7.4$ ) and subsequently centrifuged (9000 g; $4{ }^{\circ} \mathrm{C} ; 20 \mathrm{~min}$ ) in order to isolate the post-mitochondrial supernatant (PMS). The obtained supernatant fraction was distributed in new microtubes for determination of tGSH $(250 \mu \mathrm{L})$, GST $(250 \mu \mathrm{L})$, CAT $(60 \mu \mathrm{L})$, AChE $(250 \mu \mathrm{L})$ and proteins $(60 \mu \mathrm{L})$.

Those PMS samples were stored at $-80{ }^{\circ} \mathrm{C}$ until biochemical determinations, which were conducted in quadruplicate at $25^{\circ} \mathrm{C}$ with a Labsystem Multiskan EX microplate reader.

\subsubsection{Available energy reserves (Ea)}

The Ea was estimated according to De Coen and Janssen [19] by the sum of lipids, carbohydrates and proteins content, transforming them into energetic equivalents by enthalpy of combustion $(39.5 \mathrm{~kJ} / \mathrm{g}$ lipids, $17.5 \mathrm{~kJ} / \mathrm{g}$ carbohydrates and $24 \mathrm{~kJ} / \mathrm{g}$ proteins).

\subsubsection{Lipids}

The homogenate for lipid quantification was mixed with chloroform, methanol and water and centrifuged at $1000 \mathrm{xg}$ at $25^{\circ} \mathrm{C}$ for $5 \mathrm{~min}$. The organic phase was removed and transferred to a new microtube. Subsequently, sulfuric acid was added and incubated at $200{ }^{\circ} \mathrm{C}$ for $15 \mathrm{~min}$. After cooling the samples, water was added and the contents transferred to the microplates for spectrophotometer reading at $375 \mathrm{~nm}$. Tripalmitin was used as the standard.

\subsubsection{Carbohydrates and proteins}

The homogenate was added with $15 \%$ trichloroacetic acid and incubated at $-20^{\circ} \mathrm{C}$ for $10 \mathrm{~min}$. Subsequently, as samples were centrifuged at $1000 \mathrm{xg}$ at $-4{ }^{\circ} \mathrm{C}$ for $10 \mathrm{~min}$. The supernatant was removed and transferred to a new microtube for carbohydrate analysis, while the pellet was resuspended with sodium hydroxide and heated at $60{ }^{\circ} \mathrm{C}$ for $30 \mathrm{~min}$. Then, hydrochloric acid was added for neutralization and a phase was obtained for protein analysis.

Total carbohydrate content was determined with phenol and sulfuric acid. The samples were incubated at room temperature for $30 \mathrm{~min}$. After incubation, the absorbance was measured at $492 \mathrm{~nm}$, using glucose as the standard. The protein content were determined using Bradford reagente. The absorbance was read at $592 \mathrm{~nm}$ and bovine $\gamma$ globulin was used as standard. The final value was expressed in $\mathrm{mJ} /$ embryo.

\subsubsection{Energy consumption (Ec)}

Ec was measured based on the electron transport system (ETS) activity, according to Coen and Janssen [19]. The absorbance was monitored at $490 \mathrm{~nm}$ for $3 \mathrm{~min}$. The cellular consumed oxygen rate was determined using a stoichiometrical relationship ( $2 \mu \mathrm{mol}$ INT-formazan formed to $1 \mu \mathrm{mol}$ oxygen consumed). The activity was expressed in $\mathrm{mJ} /$ organism/hour.

\subsubsection{Cellular energy allocation (CEA)}

Cellular energy allocation is relation between available energy and energy consumption (CEA $=\mathrm{Ea} / \mathrm{Ec}$ ), as described by Verslycke et al. [29]. Values were expressed in $\mathrm{mJ} /$ organism.

\subsubsection{Lipid peroxidation (LPO)}

Lipid peroxidation (LPO) was determined by Ohkawa et al. [30] and Bird and Draper [31], adapted by Filho et al. [32] and Torres et al. [33]. The homogenate was separated with 2,6-ditert-butyl-4-methylphenol $4 \%$ in methanol $(\mathrm{v} / \mathrm{v})$. The LPO products were determined at $535 \mathrm{~nm}$ as thiobarbituric acidreactive substances per embryo (picomol TBARS/ embryo).

\subsubsection{Total glutathione (TG)}

Concentration of total glutathione (GSH and oxidized glutathione GSSG) was determined according to Tietze [34] and Baker et al. [35], through the reaction between a GSH and 5,5'-dithiobis (2-nitrobenzoic acid) (DTNB) in the presence of glutathione reductase (GR). Absorbance was monitored at $412 \mathrm{~nm}$ for $3 \mathrm{~min}$ and values expressed as $\mu \mathrm{M} / \mathrm{mg}$ protein.

\subsubsection{Glutathione S-transferase (GST)}

GST activity was determined according to Habig et al. [36] and adapted to microplates by Frasco and Guilhermino [37], quantifying the conjugation of glutathione to the substrate 1-chloro-2,4-dinitrobenzene (CDNB). The measurement was performed at $340 \mathrm{~nm}$ for $5 \mathrm{~min}$. The enzymatic activity was expressed in $\mathrm{nmol}$ of $\mathrm{GSH} / \mathrm{min} / \mathrm{mg}$ protein.

\subsubsection{Catalase (CAT)}

Catalase activity was determined according to Clairborne [38] by the absorbance resulting from the consumption of hydrogen. The activity was monitored for $2 \mathrm{~min}$ at $240 \mathrm{~nm}$ (ultraviolet light) and expressed in $\mu \mathrm{mol}$ of degraded peroxide $/ \mathrm{min} / \mathrm{mg}$ protein.

\subsubsection{Acetylcholinesterase (AChE)}

AChE activity was determined according to Ellman et al. [39], adapted for microplate as described in Guilhermino et al. [40], based on the velocity of thiocholine production by the hydrolysis of the acetylcholine. The activity was monitored at $414 \mathrm{~nm}$ for $5 \mathrm{~min}$ and expressed as $\mathrm{nmol} / \mathrm{min} / \mathrm{mg}$ protein.

\subsubsection{Protein quantification}

Protein quantification was performed as described by Bradford [41] and adapted to microplates according to Guilhermino et al. [40]. Bovine $\gamma$-globulin was used as standard and the spectrophotometric measurement was performed at $600 \mathrm{~nm}$.

\subsection{Data analysis}

The biochemical dataset was first evaluated for normality and homogeneity using the Kolmogorov-Smirnov and Bartlett tests, respectively. Since all data fulfilled both criteria, a one-way ANOVA was used to detect differences between the treatments for normally distributed data sets. If significant differences were found, the post hoc Dunnetts' test was used to discriminate differences between the control with DMSO and dye treatments. For the nonparametric data KruskallWallis test were performed. All statistical analyses were performed using GraphPad Prism (Ver 5.0, GraphPad Software) and statistical significance was accepted at $\mathrm{p}<0.05$.

\section{Results and discussion}

The dyes did not exert any effect on survival or hatching rate, nor did they cause any embryos malformations at any of the sublethal concentrations tested in this study. The statistical significant effects of 
Table 1

Summary of the statistical significant effects of the three different dyes evaluated on the different biochemical parameters. TG = Total Glutathione; GST $=$ Glutathione S-transferase; CAT = Catalase; LPO = lipid peroxidation; AChE $=$ acetylcholinesterase; $\quad$ LIP = lipids; $\quad$ CARB = carbohydrates; PROT $=$ proteins $; \quad \mathrm{EA}=$ available $\quad$ energy; $\quad \mathrm{EC}=$ consumed $\quad$ energy; $\mathrm{CEA}=$ cellular energy allocation. The symbols " $>$ " indicates no differences between the treatments ( $\mathrm{p}>0.05)$, whereas a " $\downarrow$ " and “ $\uparrow$ ” indicate a statistical significant decrease and increase, respectively, at the indicated test concentrations (in $\mathrm{mg} / \mathrm{L}$ ).

\begin{tabular}{|c|c|c|c|c|c|}
\hline Group & $\begin{array}{l}\text { Test } \\
\text { parameter }\end{array}$ & DR 60 & DR 73 & DR 78 & $\begin{array}{l}\text { Figure/ } \\
\text { Table }\end{array}$ \\
\hline $\begin{array}{l}\text { Non enzymatic } \\
\text { antioxidant }\end{array}$ & $\mathrm{TG}$ & $\begin{array}{l}0.01 \\
\text { and } 0.1 \\
\uparrow ; 1 \downarrow\end{array}$ & $>$ & $1 \uparrow$ & Fig. 2 \\
\hline Antioxidant & GST & $1 \downarrow$ & $>$ & $0.01 \downarrow$ & Fig. 2 \\
\hline enzymes & CAT & $>$ & $0.001 \uparrow$ & $\begin{array}{l}0.1 \uparrow ; 1 \\
\text { and } 10 \downarrow\end{array}$ & Fig. 2 \\
\hline Oxidative stress & LPO & $>$ & $>$ & $>$ & Fig. 3 \\
\hline Neurotoxicity & AChE & $>$ & $0.01 \uparrow ; 1 \downarrow$ & $10 \downarrow$ & Fig. 4 \\
\hline \multirow[t]{3}{*}{ Energy sources } & LIP & $>$ & $>$ & 1 and $10 \downarrow$ & Table 2 \\
\hline & CARB & $>$ & $>$ & $0.01-10 \uparrow$ & Table 2 \\
\hline & PROT & $>$ & $>$ & $10 \uparrow$ & Table 2 \\
\hline \multirow[t]{3}{*}{ Energy } & EA & $>$ & $>$ & $0.01-10 \downarrow$ & Table 2 \\
\hline & EC & $>$ & $1 \uparrow$ & 1 and $10 \uparrow$ & Fig. 5 \\
\hline & CEA & $>$ & $>$ & $0.01-10 \downarrow$ & Fig. 5 \\
\hline
\end{tabular}

the three dyes on the biochemical parameters evaluated are scrutinized in Table 1.

These effects are further discussed in the following subsections on conjugation, antioxidant process and oxidative stress (3.1), neurotoxicity (section 3.2), and cellular energy allocation and consumption (section 3.3). The implications of study findings for the environmental risk assessment of dyes and concluding remarks are discussed in subsection 3.4 .

\subsection{Conjugation, antioxidant processes and oxidative stress}

Intermediate DR 60 concentrations $(0.01$ and $0.1 \mathrm{mg} / \mathrm{L})$ led to increased TG levels as compared to controls (Table 1; Fig. 2). TG is known to play a critical role in the detoxification of reactive oxygen species (ROS) due to its GSH sulfhydryl-nucleophilic site that directly reacts with ROS or electrophilic substances or donates electron for enzymatic antioxidants like GST [42]. Given the absence of increased GST at these DR 60 concentrations, it appears that TG was activated for direct action or that it triggered other enzymatic antioxidants not measured in the present study, such as glutathione peroxidase or glutathione reductase [42]. The decreased TG levels in the highest DR 60 treatment, however, was accompanied with decreased GST levels (Table 1; Fig. 2), which is indicative of an impairment of conjugation and antioxidant processes that may lead to oxidative damage [43]. It hence appears that the detoxification mechanism was unable to cope with this DR 60 concentration, although no effects were noted on LPO (Table 1; Fig. 3).

Only in the lowest DR 73 concentration, an increase in CAT activity was found (Table 1; Fig. 2). CAT activity is associated with higher capacity to degrade hydrogen peroxide to avoid LPO in aquatic organisms $[11,12]$. This hence also appears to be the case in the present study since indeed no effects of DR 73 on LPO were noted (Table 1; Fig. 3). In line with this, Oropesa et al. [44] also reported increased CAT levels and absence of effects in LPO in Daphnia magna after exposure to effluents spiked with emerging contaminants.

DR 78 showed increased TG level and decreased GST activity in intermediate concentrations and decreased CAT activity in higher test concentrations (Table 1; Fig. 2). As to whether these increased TG levels were induced as a direct detoxification mechanism or due to a decreased GST activity requires further study. Despite that all three dyes had significant effects on at least one of the enzymatic activities or TG levels assessed (section 3.1; Table 1), no significant effects were noted on LPO level at any of the dye concentrations tested (Fig. 3).

\subsection{Neurotoxicity}

Decreased AChE activity was only noted at the highest test concentration of DR 73 and DR 78 (Fig. 4), indicating a low neurotoxic potential. The neurotoxic potential of dyes depends on the compound, test species and concentrations evaluated. Abe et al. [14], for example, did not encounter neurotoxic activity of the synthetic azo dye Basic Red 51 in zebrafish larvae at the concentrations evaluated. The same study, however, did demonstrate a significant reduction in AChE activity in
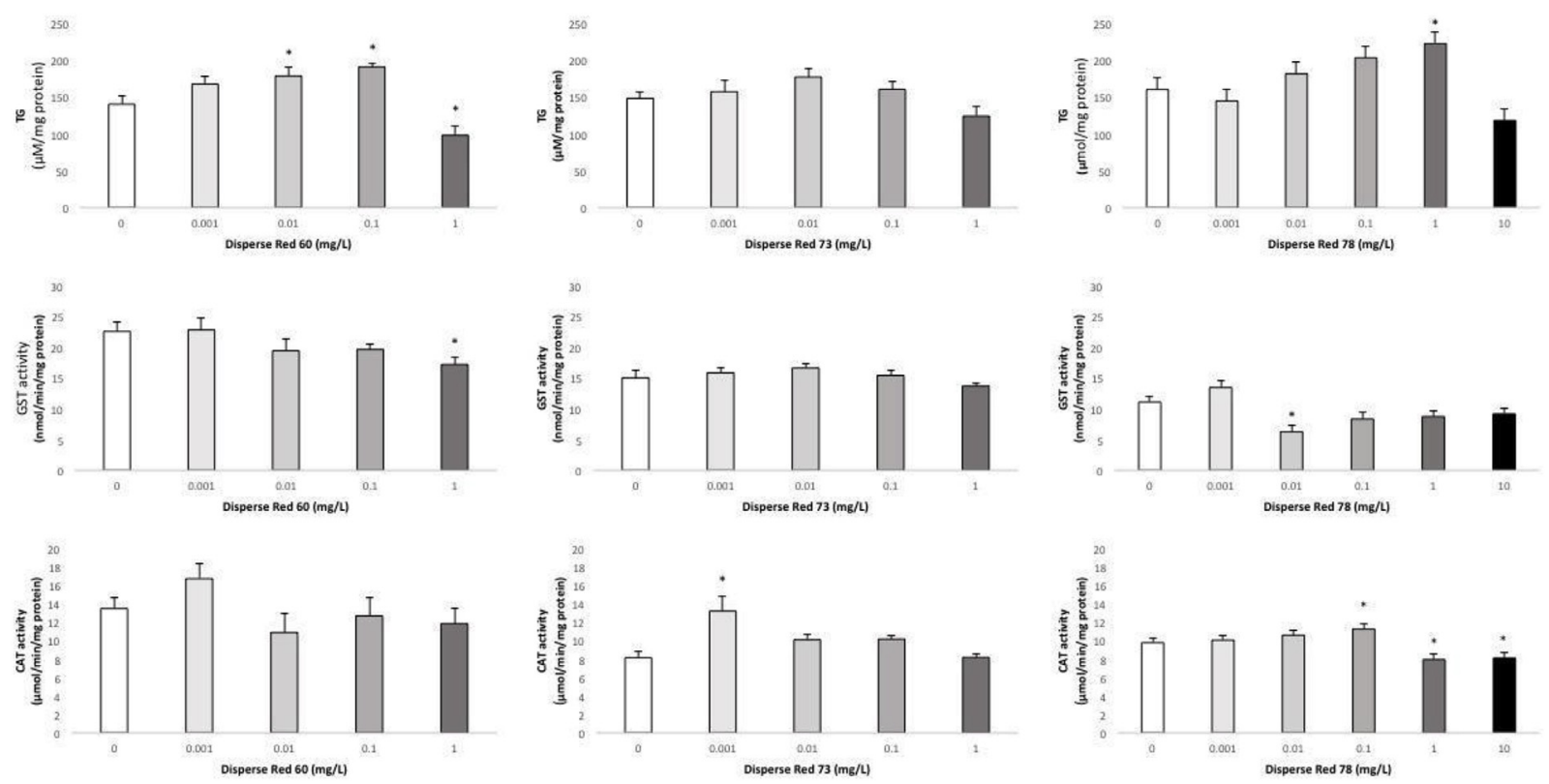

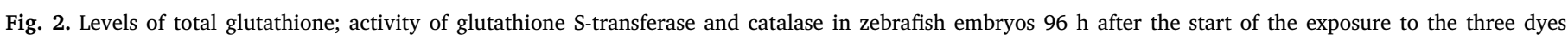
evaluated. The bars indicate mean \pm SE ( $n=8$ clusters of 20 embryos each). ${ }^{*} p<0.05$. 

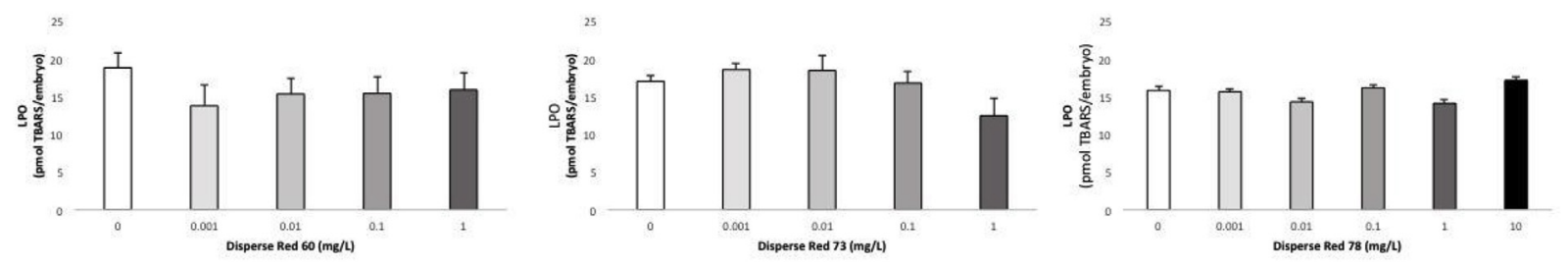

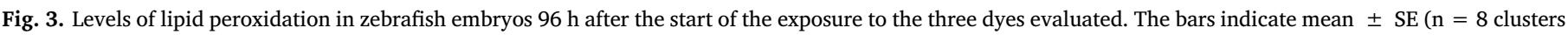
of 20 embryos each). ${ }^{*} \mathrm{p}<0.05$.
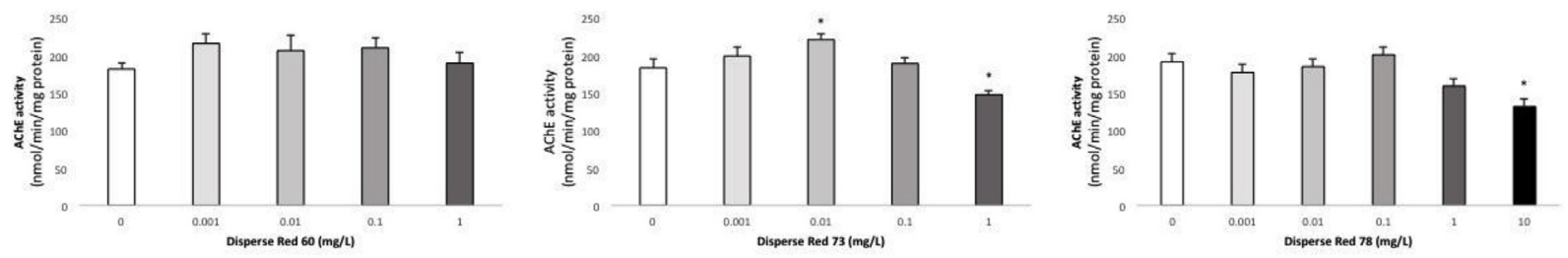

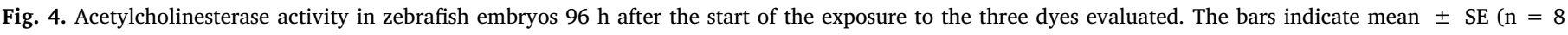
clusters of 20 embryos each). *p $<0.05$.

Table 2

Available energy (EA; mean \pm SE) and their fractions in the zebrafish embryos $96 \mathrm{~h}$ after exposure to the different dye treatments ( $\mathrm{n}=8$ clusters of $20 \mathrm{em}$ bryos each). Asterisks indicate statistical significant differences from the control (Dunnett or Kruskal Wallis test $\mathrm{p}<0.05$ ).

\begin{tabular}{|c|c|c|c|c|}
\hline \multirow[t]{2}{*}{ Treatment } & \multicolumn{3}{|c|}{ Fractions of EA (\%) } & \multirow[t]{2}{*}{ EA (mJ/embryo) } \\
\hline & Lipids & Carbohydrates & Proteins & \\
\hline \multicolumn{5}{|l|}{ DR60 } \\
\hline 0 & $94 \pm 0,9$ & $3.8 \pm 0,3$ & $2.4 \pm 0,6$ & $1908 \pm 215$ \\
\hline 0.001 & $95 \pm 0,6$ & $3.1 \pm 0,4$ & $1.9 \pm 0,3$ & $2463 \pm 252$ \\
\hline 0.01 & $94 \pm 0,8$ & $3.7 \pm 0,5$ & $1.9 \pm 0,2$ & $1728 \pm 156$ \\
\hline 0.1 & $94 \pm 1,2$ & $3.9 \pm 0,7$ & $2.8 \pm 0,5$ & $1891 \pm 367$ \\
\hline 1.0 & $93 \pm 0,8$ & $3.6 \pm 0,4$ & $3.1 \pm 0,5$ & $1979 \pm 126$ \\
\hline \multicolumn{5}{|l|}{ DR73 } \\
\hline 0 & $95 \pm 0,9$ & $3.0 \pm 0,4$ & $2.6 \pm 0,4$ & $1745 \pm 111$ \\
\hline 0.001 & $94 \pm 0,7$ & $3.3 \pm 0,4$ & $2.9 \pm 0,3$ & $1927 \pm 216$ \\
\hline 0.01 & $95 \pm 0,5$ & $3.4 \pm 0,7$ & $2.8 \pm 0,1$ & $2416 \pm 378$ \\
\hline 0.1 & $94 \pm 0,8$ & $2.8 \pm 0,4$ & $3.3 \pm 0,5$ & $2398 \pm 281$ \\
\hline 1.0 & $94 \pm 0,8$ & $2.5 \pm 0,4$ & $3.0 \pm 0,4$ & $2748 \pm 352$ \\
\hline \multicolumn{5}{|l|}{ DR7 8} \\
\hline 0 & $96 \pm 0,7$ & $2.0 \pm 0,3$ & $1.9 \pm 0,3$ & $3660 \pm 503$ \\
\hline 0.001 & $96 \pm 1,1$ & $2.1 \pm 0,4$ & $1.1 \pm 0,2$ & $2999 \pm 457$ \\
\hline 0.01 & $94 \pm 0,9$ & $4.3 \pm 0,4^{*}$ & $2.6 \pm 0,5$ & $1391 \pm 102^{*}$ \\
\hline 0.1 & $93 \pm 0,8$ & $5.0 \pm 0,5^{*}$ & $2.1 \pm 0,4$ & $1409 \pm 97^{*}$ \\
\hline 1.0 & $90 \pm 0,7^{*}$ & $5.3 \pm 0,3^{*}$ & $4.6 \pm 0,4^{*}$ & $1384 \pm 58^{*}$ \\
\hline 10 & $86 \pm 1,9^{*}$ & $6.7 \pm 0,8^{*}$ & $5.7 \pm 0,8^{*}$ & $987 \pm 116^{*}$ \\
\hline
\end{tabular}

zebrafish larvae of the natural naphthoquinone dye erythrostominone [14].

Interestingly, embryos exposed to $0.01 \mathrm{mg} / \mathrm{L}$ of the dye DR 73 were noted to have increased AChE activity (Table 1; Fig. 4). Calabrese and Baldwin [45] discussed that an increase in AChE activity may be explained as a compensatory mechanism after homeostasis alteration, and hence indicates an initial neurotoxic effect. Alternatively, this increase might be attributed to an increase of cholinergic transmission resultant from apoptotic stimulus or cell apoptosis, given its demonstrated increase in apoptotic scenarios as a potential biomarker and regulator of apoptosis $[46,47]$.

\subsection{Cellular energy allocation and consumption}

Under stress conditions, effects on energetic biomarkers have been related to the induction of detoxification processes and increased respiration, changing energy consumption, reserves and allocation $[21,48]$. In line with this, the greatest effects on energy-related biomarkers in the present study were noted for DR 78, which also showed the greatest effects on antioxidant enzymes. Besides increased energy consumption that was also noted for DR 73, the available energy was also decreased in zebrafish embryos exposed to higher DR 78 concentrations (Table 2; Fig. 5). Given that cellular energy allocation is defined as the ration between energy reserve and energy consumption [29], this test parameter was also decreased in these treatments. This increase in energy consumption for detoxification purposes indicates
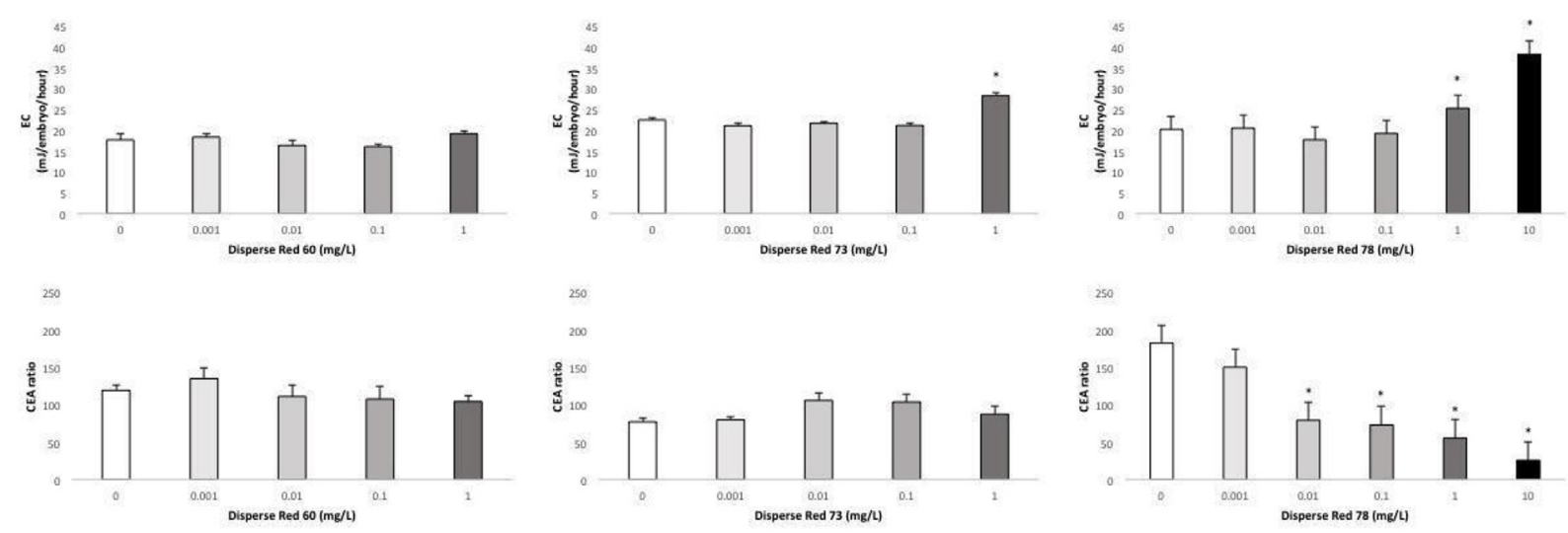

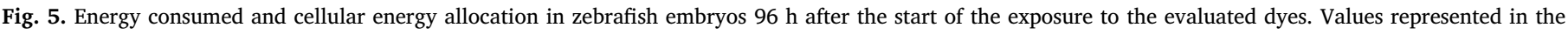
Figure indicate mean \pm SE ( $n=8$ clusters of 20 embryos each). ${ }^{*} \mathrm{p}<0.05$. 
that less energy remains available for growth and reproduction, which may lead to long-term effects on the fitness on both the individual and population level.

As can be noted from Table 2, lipids were the principle energy source in control and unaffected zebrafish embryos. In line with this, lipids in yolk reserves represent the main energy source for fish embryos $[20,49]$. On the other hand, proteins had the lowest fractions in available energy reserves, and they are indeed known to be the last choice as energy source and are hence only mobilized under severe conditions [50]. In zebrafish embryos exposed to the higher DR 78 concentrations, the increased energy consumption was accompanied with a decrease in the lipid fraction of the available energy (Table 2). In line with this, lipids have been discussed to represent the first energy source that is mobilized when organisms are exposed to chemicals, as reported for Daphnia magna [19]. The increased fraction of proteins in these treatments may be related with the increased protein synthesis utilized in the induced detoxification mechanism [20,51].

\subsection{Implications for risk assessment and concluding remarks}

Different effects on the selected oxidative stress, cellular energy allocation and neurotoxicity parameters were obtained for the different dyes, and even for different concentrations of the same dye (Table 1). Depending of the contaminant, specific antioxidant enzyme activities are indeed known to be triggered to counteract oxidative stress [13,52]. Dye concentrations may be detected from traces $(\mu \mathrm{g} / \mathrm{L})$ up to $500 \mathrm{mg} / \mathrm{L}$, depending upon the dyes and analytical methods used [3]. This indicates that the dye concentrations evaluated in the present study may exist under natural conditions and hence that they may exert toxic effects.

To ensure robustness of clothing colour and their resistance to different processes like transpiration, washing and exposure to sun, clothing dyes are designed to be persistent. Their high stability also dictates that they are relatively persistent pollutants [53,54]. For example, the half-life of the hydrolysed form of Reactive Blue 19 dye has been estimated to be 46 years [55]. Future studies are hence also needed to evaluate the chronic toxicity of dyes, the more since several studies demonstrated that dyes may need a prolonged exposure period to exert toxic side-effects $[20,56]$.

The biochemical parameters evaluated in the present study allowed assessing the cellular toxic effects induced by the dyes tested. For most chemical compounds occurring in the environment, there is often little information about their modes of action [57]. Studies at the molecular level are needed to deduct the mode of action of chemicals and hence their exact underlying toxic mechanisms. Such studies could hence also aid in developing toxicokinetic-toxicodynamic (TKTD) models that are absolutely essential for a more mechanistic understanding of chemical stress [58].

Our results clearly demonstrated that the release of the dyes DR60, DR73 and DR78 into water bodies should be carefully evaluate, taking in account the final concentration in the aquatic environmental.

\section{Funding sources}

This work was supported by National Institute of Science and Technology for Detection, Toxicological Evaluation and Removal of Emerging and Radioactive Contaminants (INCT-DATREM); São Paulo Research Foundation (FAPESP - grant number 2016/03281-9). Scholarships were provided by National Council for Scientific and Technological Development (CNPq - grant number: 142379/2014-0), Coordination for the Improvement of Higher Education Personnel (CAPES - grant number 88881.134597/2016-01) through a doctoral grant for Gabriela Meireles and São Paulo Research Foundation through a doctoral grant for Ana Letícia Madeira Sanches (FAPESP - grant number 2017/05543-3 and 2014/14621-0). Special Visiting Researcher program (MEC/MCTI/CAPES/CNPq/FAPs reference 402392/2013-2) and Portuguese government (FCT) through a postdoc grant for Michiel A. Daam (SFRH/BPD/109199/2015) and the research unit UID/AMB/ 04085/2013 (CENSE). We also acknowledge FCT for Carlos Gravato contract (IF/01401/2014) and the funding support to CESAM (UID/ AMB/50017) and co-funding by FEDER, within the PT2020 Partnership Agreement and Compete 2020.

\section{Transparency document}

Transparency document related to this article can be found online at https://doi.org/10.1016/j.cbi.2018.07.007.

\section{References}

[1] P. Rajaguru, R. Kalpana, A. Hema, S. Suba, B. Baskarasethupathi, P.A. Kumar, K. Kalaiselvi, Genotoxicity of some sulfur dyes on tadpoles (Rana hexadactyla) measured using the comet assay, Environ. Mol. Mutagen. 38 (2001) 316-322, https://doi.org/10.1002/em.10027.

[2] A. Parikh, V. Shah, D. Madamwar, Cyanobacterial flora from polluted marine shores, Environ. Monit. Assess. 120 (2006) 407-414, https://doi.org/10.1007/ s10661-005-9070-z.

[3] S. Nojavan, Z. Tahmasebi, T. Bidarmanesh, H. Behdad, M. Nasiri-Aghdam, S. Mansori, A. Pourahadi, Electrically enhanced liquid-phase microextraction of three textile azo dyes from wastewater and plant samples, J. Separ. Sci. 36 (2013) 3256-3263, https://doi.org/10.1002/jssc.201300546.

[4] W. Przystas, E. Zablocka-Godlewska, E. Grabinska-Sota, Efficacy of fungal decolorization of a mixture of dyes belonging to different classes, Braz. J. Microbiol. 46 (2015) 415-424, https://doi.org/10.1590/S1517-838246246220140167.

[5] S.M.A.G.U. Souza, E. Forgiarini, A.A.U. Souza, Toxicity of textile dyes and their degradation by the enzyme horseradish peroxidase (HRP), J. Hazard Mater. 147 (2007) 1073-1078, https://doi.org/10.1016/j.jhazmat.2007.06.003.

[6] C.J. Ogugbue, T. Sawidis, Bioremediation and detoxification of synthetic wastewater containing triarylmethane dyes by Aeromonas hydrophila isolated from industrial effluent, Biotechnol. Res. Int. 2011 (2011) 1-11, https://doi.org/10.4061/ $2011 / 967925$.

[7] J. Mathieu-Denoncourt, C.J. Martyniuk, S.R. De Solla, V.K. Balakrishnan, V.S. Langlois, Sediment contaminated with the azo dye disperse yellow 7 alters cellular stress- and androgen-related transcription in Silurana tropicalis larvae, Environ. Sci. Technol. 48 (2014) 2952-2961, https://doi.org/10.1021/es500263x.

[8] R.J. Maguire, R.J. Tkacz, Occurrence of dyes in the Yamaska River, Quebec, Water Pollut. Res. J. Can. 26 (1991) 145-161.

[9] P.A. Carneiro, G.A. Umbuzeiro, D.P. Oliveira, M.V.B. Zanoni, Assessment of water contamination caused by a mutagenic textile effluent/dyehouse effluent bearing disperse dyes, J. Hazard Mater. 174 (2010) 694-699, https://doi.org/10.1016/j. jhazmat.2009.09.106.

[10] G.J. Zocolo, G.P. dos Santos, J. Vendemiatti, F.I. Vacchi, G. de A. Umbuzeiro, M.V.B. Zanoni, Using SPE-LC-ESI-MS/MS analysis to assess disperse dyes in environmental water samples, J. Chromatogr. Sci. 53 (2015) 1257-1264, https://doi. org/10.1093/chromsci/bmu221.

[11] S. Kaur, A. Kaur, Comparative biochemistry and physiology, Part C Variability in antioxidant/detoxi fi cation enzymes of Labeo rohita exposed to an azo dye, acid black ( AB ), Comp. Biochem. Physiol., C 167 (2015) 108-116, https://doi.org/10. 1016/j.cbpc.2014.06.009.

[12] L. de Jong, N. Pech, G. de Aragão Umbuzeiro, X. Moreau, Multi-scale biomarker evaluation of the toxicity of a commercial azo dye (Disperse Red 1) in an animal model, the freshwater cnidarian Hydra attenuata, Water Res. 96 (2016) 62-73, https://doi.org/10.1016/j.watres.2016.03.043.

[13] F.R. Abe, C. Gravato, A.M.V.M. Soares, D.P. de Oliveira, Biochemical approaches to assess oxidative stress induced by exposure to natural and synthetic dyes in early life stages in zebrafish, J. Toxicol. Environ. Health Part a 7394 (2017) 1-10, https://doi.org/10.1080/15287394.2017.1371091.

[14] F.R. Abe, A.M.V.M. Soares, D.P. De Oliveira, C. Gravato, Toxicity of dyes to zebra fi sh at the biochemical level : cellular energy allocation and neurotoxicity, Environ. Pollut. 235 (2018) 255-262, https://doi.org/10.1016/j.envpol.2017.12.020.

[15] S. Rochman, Chelsea, Kurobe, Tomofumi, Flores, Ida, Teh, Early warning signs of endocrine disruption in adult fish from the ingestion of polyethylene with and without sorbed chemical pollutants from the marine environment, Sci. Total Environ. 493 (2014) 656-661, https://doi.org/10.1016/j.scitotenv.2014.06.051.

[16] W. Zhang, W. Liu, J. Zhang, H. Zhao, Y. Zhang, X. Quan, Y. Jin, Characterisation of acute toxicity, genotoxicity and oxidative stress posed by textile effluent on zebrafish, J. Environ. Sci. (China) 24 (2012) 2019-2027, https://doi.org/10.1016/ S1001-0742(11)61030-9.

[17] T. Olsen, L. Ellerbeck, T. Fisher, A. Callaghan, M. Crane, Variability in acetylcholinesterase and glutathione S-transferase activities in Chironomus riparius Meigen deployed in situ at uncontaminated field sites, Environ. Toxicol. Chem. 20 (2001) 1725-1732, https://doi.org/10.1002/etc.5620200815.

[18] S. Muthulakshmi, K. Maharajan, H.R. Habibi, K. Kadirvelu, M. Venkataramana, Zearalenone induced embryo and neurotoxicity in zebrafish model (Danio rerio): role of oxidative stress revealed by a multi biomarker study, Chemosphere 198 (2018) 111-121, https://doi.org/10.1016/j.chemosphere.2018.01.141.

[19] W. De Coen, C.R. Janssen, The use of biomarkers in Daphnia magna toxicity testing. 
IV.Cellular Energy Allocation: a new methodology to assess the energy budget of toxicant-stressed Daphnia populations, J. Aquatic Ecosyst. Stress Recovery 6 (1997) 43-55, https://doi.org/10.1023/A:1008228517955.

[20] R. Smolders, G. De Boeck, R. Blust, Changes in cellular energy budget as a measure of whole effluent toxicity in zebrafish (Danio rerio), Environ. Toxicol. Chem. 22 (2003) 890-899, https://doi.org/10.1002/etc.5620220429.

[21] I.M. Sokolova, M. Frederich, R. Bagwe, G. Lannig, A.A. Sukhotin, Energy homeostasis as an integrative tool for assessing limits of environmental stress tolerance in aquatic invertebrates, Mar. Environ. Res. 79 (2012) 1-15, https://doi.org/10.1016/ j.marenvres.2012.04.003.

[22] G. Carlsson, L. Norrgren, K. Hylland, K.E. Tollefsen, Toxicity screening of produced water extracts in a Zebrafish Embryo Assay, J. Toxicol. Environ. Health Part a 77 (2014) 600-615, https://doi.org/10.1080/15287394.2014.887424.

[23] J.L. Lyche, I.M. Grześ, C. Karlsson, R. Nourizadeh-Lillabadi, P. Aleström, E. Ropstad, Parental exposure to natural mixtures of persistent organic pollutants (POP) induced changes in transcription of apoptosis-related genes in offspring zebrafish embryos, J. Toxicol. Environ. Health Part a Curr. Issues 79 (2016) 602-611, https://doi.org/10.1080/15287394.2016.1171991.

[24] G.A.R. de Oliveira, J. de Lapuente, E. Teixidó, C. Porredón, M. Borràs, D.P. de Oliveira, Textile dyes induce toxicity on zebrafish early life stages, Environ. Toxicol. Chem. 35 (2016) 429-434, https://doi.org/10.1002/etc.3202.

[25] O.P. Rocha, C.A. Cesila, E.M. Christovam, S.B. de M. Barros, M.V.B. Zanoni, D.P. de Oliveira, Ecotoxicological risk assessment of the Acid Black 210 dye, Toxicology 376 (2017) 113-119, https://doi.org/10.1016/j.tox.2016.04.002.

[26] T. Braunbeck, B. Kais, E. Lammer, J. Otte, K. Schneider, D. Stengel, R. Strecker, The fish embryo test (FET): origin, applications, and future, Environ. Sci. Pollut. Res. Int. 22 (2015) 16247-16261, https://doi.org/10.1007/s11356-014-3814-7.

[27] C.C.I. Guaratini, V.B. Zanoni, Corantes têxteis, Quim. Nova 23 (1999) 71-78, https://doi.org/10.1590/S0100-40422000000100013.

[28] Y. Zhou, Z. Du, Y. Zhang, Simultaneous determination of 17 disperse dyes in textile by ultra-high performance supercritical fluid chromatography combined with tandem mass spectrometry, Talanta 127 (2014) 108-115, https://doi.org/10.1016/ j.talanta.2014.03.055.

[29] T. Verslycke, J. Vercauteren, C. Devos, L. Moens, P. Sandra, C.R. Janssen, Cellular energy allocation in the estuarine mysid shrimp Neomysis integer (Crustacea: Mysidacea) following tributyltin exposure, J. Exp. Mar. Biol. Ecol. 288 (2003) 167-179, https://doi.org/10.1016/S0022-0981(03)00006-6.

[30] H. Ohkawa, N. Ohishi, K. Yagi, Assay for lipid peroxides in animal tissues thiobarbituric acid reaction, Anal. Biochem. 358 (1979) 351-358, https://doi.org/10 1016/0003-2697(79)90738-3.

[31] A. Bird, R. Draper, Comparative studies on different methods of malondy-haldeyde determination, 90th ed. Meth. Enzymol. 90 (1984) 105-110.

[32] D. Wilhelm-Filho, T. Tribess, C. Gáspari, F.D. Claudio, M.A. Torres,

A.R.M. Magalhães, Seasonal changes in antioxidant defenses of the digestive gland of the brown mussel (Perna perna), Aquaculture 203 (2001) 149-158, https://doi. org/10.1016/s0044-8486(01)00599-3.

[33] M. Aloísio Torres, C. Pires Testa, C. Gáspari, M. Beatriz Masutti, C. Maria Neves Panitz, R. Curi-Pedrosa, E. Alves De Almeida, P. Di Mascio, D. Wilhelm Filho, Oxidative stress in the mussel Mytella guyanensis from polluted mangroves on Santa Catarina Island, Brazil, Mar. Pollut. Bull. 44 (2002) 923-932, https://doi.org/10. 1016/S0025-326X(02)00142-X.

[34] F. Tietze, Enzymic method for quantitative determination of nanogram amounts of total and, Anal. Biochem. 27 (1969) 502-522, https://doi.org/10.1016/00032697(69)90064-5.

[35] M.A. Baker, G.J. Cerniglia, A. Zaman, Microtiter plate assay for the measurement of glutathione and glutathione disulfide in large numbers of biological samples, Anal. Biochem. 190 (1990) 360-365, https://doi.org/10.1016/0003-2697(90)90208-q.

[36] W.H. Habig, M.J. Pabst, W.B. Jakoby, Glutathione S-transferases. The first enzymatic step in mercapturic acid formation, J. Biol. Chem. 249 (1974) 7130-7139.

[37] M.F. Frasco, L. Guilhermino, Effects of dimethoate and beta-naphthoflavone on selected biomarkers of Poecilia reticulata, Fish Physiol. Biochem. 26 (2002) 149-156, https://doi.org/10.1023/A:1025457831923.

[38] A. Clairborne, Catalase activity, CRC Handb Methods Oxyg Radic Res., Boca Raton, Greenwald, R.A, 1985.

[39] G.L. Ellman, K.D. Courtney, V. Andres, R.M. Featherstone, A new and rapid colorimetric determination of acetylcholinesterase activity, Biochem. Pharmacol. 7
(1961) 88-95, https://doi.org/10.1016/0006-2952(61)90145-9.

[40] L. Guilhermino, M.C. Lopes, A.P. Carvalho, A.M.V.M. Soares, Inhibition of acetylcholinesterase activity as effect criterion in acute tests with juvenile Daphnia magna, Chemosphere 32 (1996) 727-738, https://doi.org/10.1016/0045-6535(95) 00360-6.

[41] M. Bradford, A rapid and sensitive method for the quantification of microgram quantities of protein utilizing the principle of protein dye binding, Anal. Biochem. (1976) 248-254, https://doi.org/10.1016/0003-2697(76)90527-3.

[42] D. Trachootham, W. Lu, M.A. Ogasawara, N.R.-D. Valle, P. Huang, Redox regulation of cell survival, Antioxidants Redox Signal. 10 (2008) 1343-1374, https://doi.org/ 10.1089/ars.2007.1957.

[43] W. Zhang, W. Liu, J. Zhang, H. Zhao, Y. Zhang, X. Quan, Y. Jin, Characterisation of acute toxicity, genotoxicity and oxidative stress posed by textile effluent on zebrafish, J. Environ. Sci. (China) 24 (2012) 2019-2027, https://doi.org/10.1016/ S1001-0742(11)61030-9.

[44] A.L. Oropesa, S.C. Novais, M.F.L. Lemos, A. Espejo, C. Gravato, F. Beltrán, Oxidative stress responses of Daphnia magna exposed to effluents spiked with emerging contaminants under ozonation and advanced oxidation processes, Environ. Sci. Pollut. Res. 24 (2017) 1735-1747, https://doi.org/10.1007/s11356-016-7881-9.

[45] E.J. Calabrese, L. a Baldwin, Inorganics and hormesis, Crit. Rev. Toxicol. 33 (2003) 215-304, https://doi.org/10.1080/713611040.

[46] H. Jiang, X.J. Zhang, Acetylcholinesterase and apoptosis: a novel perspective for an old enzyme, FEBS J. 275 (2008) 612-617, https://doi.org/10.1111/j.1742-4658. 2007.06236.x.

[47] T.S. Andrade, J.F. Henriques, A.R. Almeida, A.L. Machado, O. Koba, P.T. Giang, A.M.V.M. Soares, I. Domingues, Carbendazim exposure induces developmental, biochemical and behavioural disturbance in zebrafish embryos, Aquat. Toxicol. 170 (2016) 390-399, https://doi.org/10.1016/j.aquatox.2015.11.017.

[48] J. Choi, H. Roche, T. Caquet, Hypoxia, hyperoxia and exposure to potassium dichromate or fenitrothion alter the energy metabolism in Chironomus riparius $\mathrm{Mg}$. (Diptera: Chironomidae) larvae, Comp. Biochem. Physiol. C Toxicol. Pharmacol. 130 (2001) 11-17, https://doi.org/10.1016/S1532-0456(01)00206-X.

[49] D. Fraher, A. Sanigorski, N.A. Mellett, P.J. Meikle, A.J. Sinclair, Y. Gibert, Zebrafish embryonic lipidomic analysis reveals that the yolk cell is metabolically active in processing lipid, Cell Rep. 14 (2016) 1317-1329, https://doi.org/10.1016/j.celrep. 2016.01.016.

[50] M.J. McKee, C.O. Knowles, Protein, nucleic acid and adenylate levels in Daphnia magna during chronic exposure to chlordecone, Environ. Pollut. Ecol. Biol. 42 (1986) 335-351, https://doi.org/10.1016/0143-1471(86)90017-6.

[51] S.C. Novais, M.J.B. Amorim, Changes in cellular energy allocation in Enchytraeus albidus when exposed to dimethoate, atrazine, and carbendazim, Environ. Toxicol. Chem. 32 (2013) 2800-2807, https://doi.org/10.1002/etc.2368.

[52] C. Gravato, J.R. Almeida, C. Silva, C. Oliveira, A.M.V.M. Soares, Using a multibiomarker approach and behavioural responses to assess the effects of anthracene in Palaemon serratus, Aquat. Toxicol. 149 (2014) 94-102, https://doi.org/10.1016/j. aquatox.2014.01.024.

[53] C. O'Neill, F.R. Hawkes, D.L. Hawkes, N.D. Lourenço, H.M. Pinheiro, W. Delée, Colour in textile effluents - sources, measurement, discharge consents and simulation: a review, J. Chem. Technol. Biotechnol. 74 (1999) 1009-1018, https://doi. org/10.1002/(SICI)1097-4660(199911)74:11<1009::AID-JCTB153> 3.0.CO;2-N

[54] K.T. Chung, Mutagenicity and carcinogenicity of aromatic amines metabolically produced from azo dyes, J. Environ. Sci. Health Part C Environ. Carcinog. Ecotoxicol. Rev. 18 (2000) 51-74, https://doi.org/10.1080/10590500009373515.

[55] O.J. Hao, H. Kim, P.C. Chiang, Decolorization of wastewater, Crit. Rev. Environ. Sci. Technol. 30 (2000) 449-505, https://doi.org/10.1080/10643380091184237.

[56] L. Moolman, J.H.J. Van Vuren, V. Wepener, Comparative studies on the uptake and effects of cadmium and zinc on the cellular energy allocation of two freshwater gastropods, Ecotoxicol. Environ. Saf. 68 (2007) 443-450, https://doi.org/10.1016/ j.ecoenv.2006.12.017.

[57] A. Kienzler, S.K. Bopp, S. van der Linden, E. Berggren, A. Worth, Regulatory assessment of chemical mixtures: requirements, current approaches and future perspectives, Regul. Toxicol. Pharmacol. 80 (2016) 321-334, https://doi.org/10. 1016/j.yrtph.2016.05.020

[58] T. Jager, E.M. Gudmundsdóttir, N. Cedergreen, Dynamic modeling of sublethal mixture toxicity in the nematode Caenorhabditis elegans, Environ. Sci. Technol. 48 (2014) 7026-7033, https://doi.org/10.1021/es501306t. 